\title{
LA CUESTIÓN DE LA «LEY DEL CANDADO» EN LAS ELECCIONES PROVINCIALES DE ÁLAVA
}

POR

\author{
ONÉSIMO DÍAZ HERNÁNDEZ
}

\section{RESUMEN}

En este trabajo se pretende mostrar la repercusión en los partidos de la derecha alavesa de las medidas de gobiemo anticlericales del Partido Liberal a través de las elecciones de 1907 y 1911 en la provincia de Álava.

\section{Abstract}

This article shows the repercussion of the Government's measures of the Liberal Party against the Conservative Parties in Alava during the elections of 1907 and 1911.

En este trabajo se pretende mostrar la repercusión en los partidos de la derecha alavesa de las medidas de gobierno anticlericales del Partido Liberal a través de las elecciones de 1907 y 1911 en la provincia de Álava.

\section{El aNTiClericalismo español a PRINCIPIOS DEL SIGLO XX}

En cierta medida, el creciente papel representado por la religión católica en la vida española fue consecuencia de la respuesta de las derechas ante las medidas anticlericales adoptadas por los sucesivos gobiernos liberales de principios 
de siglo ${ }^{1}$. El fin perseguido por los gabinetes de los sucesores de Sagasta fue la separación lo más amplia posible del Estado y de la Iglesia, tal como se había logrado recientemente en Francia. Para conseguirlo elaboraron una serie de proyectos (sobre matrimonios y cementerios civiles, el catecismo en las escuelas, la «ley del candado» y el proyecto sobre una nueva ley de asociaciones religiosas, entre otras), que pretendían limitar los derechos y los privilegios adquiridos por algunas instituciones eclesiásticas. Las medidas de corte liberal y anticlerical fueron defendidas por el Partido Liberal con el apoyo de los republicanos y socialistas.

Los primeros disturbios anticlericales -en ocasiones llamados antijesuíticos por la prensa- se produjeron en la segunda quincena del mes de marzo de 1901. La Libertad, el diario liberal de Álava, describió los acontecimientos acaecidos en Castellón, La Coruña, Valladolid, Jaen, Baracaldo, Bilbao, Barcelona, Madrid, Las Palmas y otros lugares. Normalmente fueron actos con motivo de reivindicaciones laborales, o bien relacionados con protestas y enfrentamientos por la representación de la obra teatral de Galdos Electra, o bien conectados con la celebración de procesiones católicas ${ }^{2}$.

En el último censo realizado, Álava ocupaba el sexto lugar en cuanto a porcentaje de comunidades religiosas respecto al resto de población de la provin$\mathrm{cia}^{3}$. Este dato significativo y el talante conservador y tradicional de la mayor parte de los habitantes de la capital -denominada por algunos «ciudad levíticas- $y$, sobre todo del entorno rural alavés parecen apuntar a que el rechazo pudo ser mayor y más unánime en Álava que en otras provincias españolas. Una prueba -entre muchas- fue el elevado número de firmas recogidas de protesta contra algunas medidas gubernamentales o la asistencia multitudinaria a las manifestaciones autotituladas católicas, que movilizaron a grupos políticos y amplios sectores de la sociedad conservadora alavesa. La contestación a la abrumadora protesta clerical fue realizada por los republicanos, conscientes de la necesidad del aumento de libertades, que debian traer consigo un ambiente favorable de cara a la proclamación de la República. Los republicanos contaron con el débil y testimonial apoyo de los canalejistas, socialistas y anarquistas alaveses.

\footnotetext{
I Cfr. J. ANDRÉs-Gallego, Historia General de España y América, vol. XVI-2, Madrid, Rialp, 1981, p. 420; J. ANDREs-Gallego, La política religiosa en España, 1899-1913, Madrid, Nacional, 1975, p. 511; J. VARELA, Los amigos politicos. Partidos, elecciones y caciquismo en la Restauración (1875-1900), Alianza, Madrid, 1977, p. 338.

${ }^{2}$ Cfr. La Libertad (15-30.III.1901). 121.

${ }^{3}$ Cfr. M. Revuelta, El anticlericalismo español en sus documentos, Barcelona, Ariel, 1999, p.
} 
La cuestión religiosa se tradujo paradójicamente en Álava en dos fenómenos interrelacionados: la movilización de las derechas en pro de la defensa de buena parte del ideario católico, que había sido encorsetado por las leyes liberales y, por otra parte, el freno al avance del proceso secularizador como factor importante de la modernización política y del avance social ${ }^{4}$. Por un lado, la agitación de los partidos carlistas e integristas con amplio y variado apoyo social significó la consolidación de los grupos tradicionalistas en Álava como verdaderos partidos de amplia base popular. Sin embargo, las masas no tenían apenas un papel decisorio en los órganos directivos de las derechas, aunque la participación en los actos políticos y electorales fueron manifestaciones de la conciencia creciente del valor de las bases en el entramado político y social de los partidos tradicionalistas. Por tanto, las derechas movilizaron a mayor número de personas que las izquierdas, aunque de manera un tanto interesada, puesto que las bases fueron empleadas para un fenómeno puntual y después condenadas al ostracismo y apartadas de cualquier intento de democratización de los partidos de la derecha, que iría en contra de su propia idiosincrasia, de carácter elitista y nada democrático.

Para los republicanos la cuestión anticlerical fue interpretada como el estandarte del progreso y advenimiento de la República. Las bases de los grupos republicanos acudieron a los mítines y manifestaciones a favor de las medidas laicas del gobierno. El papel de los afiliados republicanos fue mucho más dinámico que el de los tradicionalistas, especialmente por la importancia de las asambleas generales celebradas con el fin de decidir las cuestiones candentes del partido. Los republicanos fueron quienes más exhortaron en favor de la democratización del régimen y del fin de la corrupción electoral, que podía desembocar tarde o temprano en la vuelta de la República.

En relación con el auge de la cuestión anticlerical y el proceso de secularización social -que no se debe reducir a la pérdida de los valores religiosos-, podemos decir que los partidos con amplio cierto popular y ajenos al tinglado del bipartidismo, tanto los republicanos como -sobre todo- los tradicionalistas en Álava, experimentaron una cierta consolidación al movilizar a las bases en torno a la política gubernamental en temas religiosos. Queremos subrayar esta idea, puesto que hasta principios del siglo XX la motivación política en Álava había estado circunscrita a temas locales y de escasa transcendencia. Por otra parte, por la condición de partidos ajenos al sistema turnista de acceso al poder

4 Cfr. T. CARNERo, «Modemización política: una propuesta de análisis», Historia Contemporánea, n. ${ }^{\circ}$ 4, 1990, pp. 133-145; «Política sin democracia en Espaha, 1874-1923», Revista de Occidente, n. ${ }^{\circ}$ 83, 1988, pp. 43-59; T. CARNERo (ed.), Modernización, desarrollo político y cambio social, Madrid: Alianza, 1992; «El reinado de Alfonso XIII», Ayer, $\mathbf{n}^{\circ} 28,1997$. 
(en el sistema político de la Restauración sólo podían gobernar los partidos del turno: unas veces los conservadores y otras los liberales), pensamos que fueron conscientes de la transcendencia de la solución del problema religioso, que podía desembocar en un régimen democrático y republicano con libertad de cultos, libertad de enseñanza y otras libertades, $o$ bien en un régimen político basado en la unidad católica, la defensa de la unión entre el Estado y la Iglesia, que pusiese límite a las libertades liberales. En suma, a pesar de la agitación de los partidos de base popular en Álava en los primeros años del nuevo siglo el pequenio progreso político no fue acompañado por cambios sociales, económicos y políticos más profundos. Por tanto, Álava permaneció como una provincia muy conservadora.

\section{LAS ELECCIONES DE 1907}

Tanto en las elecciones provinciales como en las generales de 1907 el tema central del debate político fue la cuestión religiosa, centrada en el proyecto de Ley de Asociaciones, que había sido aprobado en el consejo de ministros presidido por el liberal López Domínguez (6.VII.1906-30.XI.1906), aunque todavía era un simple proyecto. En esta misma línea el gabinete liberal había aprobado una real orden sobre el matrimonio y los cementerios civiles, y anunció otras medidas con el fin de controlar las órdenes religiosas 5 .

Progresivamente las relaciones con la Santa Sede se enrarecieron y la jerarquía eclesiástica española promovió las Ligas Católicas o Juntas de Defensa Católica en todas las provincias con el fin de impedir que prosperase el proyecto sobre las Asociaciones ${ }^{6}$. La Junta de Álava, que se constituyó el 12 de diciembre de $1906^{7}$, con los siguientes cargos: presidente el marqués de la Alameda, el maurista José María Zavala; vicepresidente el diputado provincial integrista Benito Guinea; tesorero el independiente Cipriano del Valle y vicetesorero otro independiente Eulogio Olavide; secretario: el ex-diputado provincial carlista Ramón Ortiz de Zárate y vicesecretario el independiente Gregorio González de Suso. Una de las primeras decisiones fue el envio de una carta de protesta a las Cortes, firmada por la mitad de los alaveses, contra «una campania antirreligiosa calcada en leyes exóticas» -en palabras del diario oficial de la campana, el tradicionalistaHeraldo Alavés- «en que se funda la ley de Aso-

\footnotetext{
${ }^{5}$ Cfr. Archivo Romanones, 38-75.

6 Cfr. Boletín Eclesiástico del Boletín de Vitoria (BEOV), 15.I.1907, pp. 6-7.

7 Cfr. Heraldo Alavés (HA), 13.XII.1906, «Una Junta. La defensa católica»; La Libertad, 15.III.1907, «Lo inevitable».
} 
ciaciones pendiente de discusión en el Congreso» ${ }^{8}$. Los obispos -también el de Vitoria- fueron respaldados por los conservadores, los carlistas y los integristas y una parte considerable de la opinión pública. En la circular que envió el obispo de Vitoria a todos los católicos de la provincia, en primer lugar, recalcó el contexto de persecución religiosa: «La doctrina católica es combatida (...) radicalismos que nos parecen exóticos en nuestra patria nos obligan a rechazarlos» $-\mathrm{y}$ a continuación, erigió (por iniciativa propia y personal la Junta de defensa católica con carácter permanente, dando cabida en ellas a distinguidas personalidades.)

La provincia española que aportó más firmas contra la ley de Asociaciones fue Álava'. Las firmas recogidas a los mayores de quince años fueron 50.402 sobre una población que rondaba los 100.000 habitantes. Los pliegos en blanco y las instrucciones de la recogida de firmas estuvieron en una oficina habilitada en el palacio episcopal. En este proceso se movilizaron laicos y clérigos a través de las asociaciones y cofradías establecidas en las parroquias y en los conventos. Las firmas se depositaron en las sacristías de las parroquías ${ }^{30}$. Conviene subrayar la importancia de la movilización de la opinión pública, que hasta los albores del siglo XX había aparecido abúlica o adormecida, pero con el cambio de siglo y ante unos temas que le afectaban directamente optaron por mostrar su opinión hasta este momento muda y, en ocasiones, silenciada.

$\mathrm{El}$ proceso de modernización de la sociedad espafiola fue acompanfado de la desacralización o secularización de la sociedad, o más bien, los intentos de secularizar el Estado. En este sentido, el Partido Liberal llevó a cabo una serie de medidas en aras al fortalecimiento del Estado en detrimento de las poderosas órdenes religiosas. En 1901, el conde de Romanones centralizó el servicio de

${ }^{8} \mathrm{HA}, 17 . \mathrm{XII} .1906$, «La defensa católica».

9 Cfr. HA, 24.XII.1906, «Junta de Defensa Católica»; 2.I.1907, «Junta de Defensa Católica»; 10.I.1907, «De Defensa Católica». El Heraldo fue el portavoz de la Junta de Álava y, en cambio, $L a$ Libertad propugnó la unión de los antireaccionarios y la defensa de la tolerancia (cfi. LL, 1.11.1907, "Tolerancia»; 4.II.1907, «El bloque») y se autoproclamó órgano del incipiente «bloque de todas las izquierdas, contra la amalgana reaccionaria. Republicanos, socialistas, liberales» (LL, 15.J.1907, "por la libertads).

${ }^{10}$ El Heraldo destacó el elevado número de católicos (50.000) que protestaron en Pamplona (9.XII.1906) contra la ley mientras sólo un reducido grupo de radicales $(2.000)$ se manifestó en contra de la amenaza clerical (cfr. HA, 18.XII.1906, «Fracaso»; LL, 23.XII.1906, «Provincias»). Sobre la manifestación de Pamplona efr. J. ANDRÉs-GaLlego, Historia Contemporánea de Navarra, Pamplona, Ediciones y Libros, 1982, pp. 58-59. En Bilbao acudieron 60.000 católicos -el doble que en la capital guipuzcoana-que escucharon un telegrama del Obispo que decia: «uno mi protesta a la vuestra valiente contra anticatólico y afrancesado proyecto de Ley de Asociaciones» (BEOV, 15.1.1907, pp. 6-7). En Vitoria no llegó a celebrarse la manifestación porque fue convocada pocos días después de la llegada de Maura al poder. 
enseñanza primaria tanto en el aspecto financiero como en la gestión y, más tarde, en virtud de otro decreto limitó la enseñanza del catecismo en las escuelas. La aprobación del matrimonio y de los cementerios civiles por parte de otro gobiemo liberal en 1906 y la posible promulgación de la ley de asociaciones religiosas fueron los hitos que provocaron una agitación de las masas sin parangón hasta entonces en la Restauración. En efecto, la incipiente intervencion del Estado en la enseñanza y las medidas de control de las congregaciones religiosas podían acelerar la secularización de la sociedad. Lo mismo que sucedió en otros lugares, la irrupción del proceso secularizador en la primera década del siglo XX -con más fuerza que anteriormente- fue acompañado de una mayor agitación social, tanto en la capital vitoriana como en el resto de la provincia.

En las elecciones provinciales de 1907 vencieron los candidatos carlistas. Evidentemente, la participación fue alta, en torno al ochenta por ciento. De los 4.542 electores votaron 3.138. Un cronista del Heraldo comentó que «no se han conocido elecciones que más hayan apasionado los ánimos ${ }^{11}$. Por los comentarios de la prensa y la ausencia de protestas en las comisiones de actas de la diputación, parece que fue una elección pacífica, sin apenas violencia ni mucha compra de votos. Entre los factores explicativos de la elevada votación no podemos olvidar la presentación de sólo dos candidaturas, con candidatos de cierto nivel socio-económico y algunos con experiencia política, que respondían a los intereses del hegemónico carlismo en el distrito de Laguardia frente al poder dinástico de la familia Urquijo interesado en el control político de toda la provincia y, en cierto modo, pendiente de cualquier crecimiento desmesurado del fenómeno tradicionalista ${ }^{12}$. Y, sobre todo, la indicación del Obispo en la pastoral leída el domingo previo a las elecciones exhortando a los católicos que votasen, incluso que podían pecar si no votaban: «Puede pecar mortalmente quien se abstiene de votar cuando eso sea causa de que no sea elegido el candidato bueno 0 salga triunfante el hostil a la Iglesia» ${ }^{13}$.

Los juicios emitidos por parte de la prensa sobre esta elección fueron diametralmente opuestos. La Libertad achacó la victoria carlista a la actividad desplegada por la Junta de Defensa Católica y que «la autoridad eclesiástica ha prevenido y ha recomendado a los electores que den su voto a unas personas y lo nieguen a otrass $)^{14}$. En efecto, el Obispo envió a las parroquias una pastoral, que fue leída un domingo poco antes del sufragio, pidiendo el voto al candidato más católico. Y esta indicación fue aplaudida por el Heraldo por considerar necesa-

\footnotetext{
1 HA, 12.II.1907, «Actualidad regional».

12 Cfr. O. Díaz HeRnández, Los Marqueses de Urquijo, Pamplona, Eunsa, 1998.

${ }^{13}$ BEOV, 5.III.1907, pp. 89 ss.

14 LL, 12.III.1907, «Triunfos clericales».
} 
rio que el Prelado exhortase a votar al candidato más católico tras una época caracterizada por leyes que estaban poniendo en peligro la situación tradicional (aprobación de Ios matrimonios y cementerios civiles, proyecto de ley de Asociaciones, etcétera) ${ }^{15}$. En cambio, La Libertad se equivocó al involucrar a la Junta de Defensa Católica en esta elección, puesto que o no pudo-por la táctica carlista de presentarse en solitario- o no quiso tomar parte en los comicios -postura imparcial también tomada en las elecciones generales, poco después ${ }^{16}$.

En las elecciones generales, el cacique omnipresente en la política y la economía alavesa Juan Cano Aldama intentó que el fracaso cometido en las provinciales de extender el cacicato urquijista al distrito de Laguardia, no se repitiese y procuró subsanarlo con el apoyo del gobernador civil y de la diputación. El gobernador Ebro se reunió con dinásticos de distinto signo -con predominio conservador-y manifestó que la combinación gubernamental para los distritos de Amurrio, Laguardia y Vitoria era Estanislao Urquijo, J. Hurtado de Amézaga y Eduardo Dato, respectivamente. En esta reunión el presidente de la Junta de Defensa Católica manifestó que la junta había acordado abstenerse de tomar parte en las próximas elecciones, tal como había hecho en las provinciales ${ }^{17}$. Las candidaturas y la campana de las elecciones generales sufrieron varias mutaciones.

Finalmente, Estanislao Urquijo fue reelegido en su feudo. Dato -apodado "el fugitivo" por el ministro de Gobernación ${ }^{18}$ - se retiró y permitió la reelección del republicano Llorente gracias al enfrentamiento de dos candidatos carlistas, Zárate apoyado por la juventud y la vieja militancia carlista contra Esteban Bilbao respaldado por los «primates» del Partido. Y en Laguardia venció el cunero carlista Alcocer también favorecido por el enfrentamiento de dos candidatos del mismo signo, esta vez dos liberales, Hurtado de Amezaga frente a Martínez de Aragón ${ }^{19}$. De nuevo, volvieron a arreciar las críticas contra el obispo culpado de hacer campaña en pro de algunos candidatos. Cadena y Eleta, que sufrió presiones del ministro de la Gobernación para que se pronunciase a favor de Dato y también fue coaccionado por parte de los carlistas, manifestó

\footnotetext{
15 Cfr. HA, 12.III.1907, «Actualidad regional».

${ }^{16}$ En las bases del reglamento de la Junta de Defensa de Álava en ningún momento se mencionó la intención de presentar candidatos en política o hacer actividades relacionadas con las elecciones (cfr. BEOV, 19.XII.1906).

${ }^{17}$ Cfr. LL, 15.III.1907, «Las próximas elecciones».

is Cfr. Archivo Moura, Leg. 156, carta de J. de la Cierva a A. Maura, 6.IV.1907: «Veremos si hay medio de sustituir al fugitivo (...) Lástima grande ha sido esto, pues la elección se puede decir que estaba asegurada.",

19 Cfr. LL, 15.III.1907, 6.IV.1907, 13.IV.1907; HA, 22. IV.1907; LL, 26.IV.1907; Archivo Maura, Leg. 156, 23.IV.1907; leg. 107, carta de Julio Urquijo a A. Maura, 29.IV.1907.
} 
que no se inclinaba oficialmente hacia ninguna de las candidaturas católicas ${ }^{20}, y$ que sólo había aclarado que los católicos «pueden libremente y sin faltar a su conciencia emitir su sufragio a favor de un candidato siempre que este sea católico" ${ }^{21}$. La Libertad aprovechó la campaña para criticar desde su punto de vista anticlerical al obispo: «los carlistas se encuentran con que el Prelado con Dato se queda y con que Bilbao, bendito y todo por el Ordinario de la Sede es desbancado por el ex-ministro conservadorn ${ }^{22}$.

\section{LAS ELECCIONES DE 1911 Y «LA LEY DEL CANDADO»}

Durante el gobierno de Canalejas (10.11.1910-12.XI.1912) se experimentó un crecimiento de los partidos de izquierda -canalejistas, republicanos y socialistas- menos en Álava y otras escasas excepciones. Las victorias tradicionalistas en las elecciones municipales y generales en Álava durante los anios del trienio de Canalejas, sólo fueron frenadas en las elecciones provinciales de 1911, tal como veremos más adelante.

De otra parte, las medidas anticlericales -que no eran irreligiosas ni antirreligiosas en el fondo, aunque en la forma debían haber contado con la Santa Sede para disminuir el número de congregaciones, ya que era materia concordada- adoptadas por el gobierno canalejista -libertad de cultos, libertad de enseñanza y control sobre las órdenes religiosas-- encontraron una fuerte oposición.en la provincia ultraconservadora de $\mathrm{Alava}^{23}$. Una Real Orden había permitido que los templos no católicos mostraran signos propios en el exterior y poco después la capilla protestante abierta en la capital alavesa fue objeto de todo tipo de vejaciones, hasta que fue cerrada ${ }^{24}$. Los mítines y las manifestaciones contra la ley de Asociaciones y las escuelas neutras o laicas se sucedieron sin solución de continuidad por toda la provincia (Vitoria, Laguardia, Salvatierra, Izarra, Valdegovía, etcétera) ${ }^{25}$. Tampoco faltaron la celebración de actos

${ }^{20}$ Cfr. HA, 18.IV.1907, «En el Obispadon, 126; 132;

${ }^{2 t}$ LL, 19.IV.1907, «Otra pastoral».

${ }^{22}$ LL, 19.1II.1907, «Los primates».

${ }^{23}$ Cfr. LL, 30.V.1910, «Política activa».

24 En 1908 quisieron los protestantes abrir una capilla evangélica, pero las antoridades lo impidieron con la escusa de que el local arrendado era insalubre (Cfr. LL, 11.VII.1910).

${ }^{25}$ Cfr. HA, 3.XII. 1909; 19.II.1910, "Contra las escuelas laicas. El mitin de mañana en Vitoria»; 25.Il.1910, «El mitin de Laguardia. Contra las escuelas laicas»; LL, 26.II.1910, «La unión de las derechas»; HA, 30.III.1910, «Contra las escuelas sin Dios»; 14.VII.1910, «i Católicos!! a la Virgen del Castillo»; 18.VII.1910, «El acto de ayer»; 13.X.1910, «Manifestación católica. A los católicos de Valdegovia»; 20.X.1910, «desde Valdegovia».

Actas del I Congreso de Historia de la Iglesia y el Mundo Hispánico Hispania Sacra, 52 (2000) 
litúrgicos y la recogida de firmas para manifestar la protesta contra las medidas anticlericales ${ }^{26}$.

La movilización de los grupos derechistas -integristas, carlistas, nacionalistas y conservadores- fue la mayor hasta el momento, y -en buena parte- gracias a esta actividad propagandística obtuvieron los excelentes resultados en las elecciones municipales y generales durante el trienio canalejista en Álava. E1 acto más multitudinario y completo tuvo lugar en Vitoria, el 2 de octubre de 1910. Tras la Misa, se celebró un mitin y terminó el acto con una manifestación por las principales calles de Vitoria ${ }^{27}$. Según el Heraldo asistieron más de quince mil personas, y según La Libertad alrededor de seis mil. Parece más verosimil que probablemente acudieran a la manifestación alrededor de điez mil ${ }^{28}$.

Dentro de la cuestión religiosa la más problemática fue la ley de Asociaciones, denominada vulgarmente «ley del candado" ${ }^{29}$. El objeto de la ley era que el ministerio de Gracia y Justicia controlase el número y la composición de las congregaciones -por ejemplo: no se permitió que más de un tercio de los religiosos fuesen extranjeros-, mientras no se dictase una nueva ley reguladora del derecho de asociación ${ }^{30}$. Inmediatamente, tras la aparición de la Real Orden del ministerio de la Gobernación (30.V.1910) sobre las Asociaciones religiosas, el gobernador interino de Álava Federico Baráibar pidió a los alcaldes de la provincia que remitiesen la relación completa (nombre, lugar de residencia, tipo de orden, dedicación, si estaban inscritos en el registro del gobierno de la provincia, el número de miembros de la asociación, la fecha de su establecimiento y el nombre de los superiores) de las congregaciones de carácter regular o monástico. De la información remitida al gobernador queremos subrayar que en los últimos cuarenta afios se establecieron en Vitoria veinte nuevas comunidades religiosas. Otro dato significativo fue que de los ochenta y ocho religiosos varones, que pertenecian a seis órdenes, establecidos en Vitoria cincuenta eran extranjeros. Y de las cuatrocientas treinta y dos religiosas, que pertenecian a veinte asociaciones, setenta y cuatro eran extranjeras

${ }^{26}$ Cfr. HA, 28.VI.1910, «Protestemos. Los actos de mañana»; 30.VI.1910, «Oraciones y protestas»; LL, 9.VII.1910, «Hojas carcas».

${ }_{27}$ Cfr. HA, 2.X.1910, «Un gobierno impopulan;; «Final»; L.L, 3.X.1910, «Las manifestaciones carlo-integristas-bizcaitarras»; 4.X.1910, «El fracaso de los católicos». La Libertad calculó que un $80 \%$ eran jaimistas, el $16 \%$ integristas, el $3 \%$ nacionalistas y el resto conservadores.

${ }^{28}$ Heraldo Alavés llegó a la mayor tirada que ningún periódico había alcanzado en Vitoria: seis mil fueron los números (cfr. HA, 3.X.1910, «La protesta católica. Nuestro triunfon).

${ }^{29}$ Cfr. LL, 9.VII.1910, «Asociaciones religiosas en Vitoria». Sobre la cuestión en Álava cfr. HA 3.VI.1910, «La persecución religiosa»; 11.VII.1910, «Notas vitorianas».

${ }^{30}$ Cfr. LL, 24.X.1910, «La Ley del Candado». La muerte de Canalejas y la fuerte oposición a la ley impidieron la aparición de la definitiva ley de asociaciones, ya que la ley aprobada a finales de 1910 (24.XII.1910) preveja que si en dos afios no se promulgaba una nueva ley aquella quedaría sin efecto. 
Así las cosas, las izquierdas (canalejistas, republicanos y socialistas) también se movilizaron, aunque en proporciones más modestas en una provincia tan conservadora. A través de manifestaciones, mítines y banquetes intentaron no «permanecer cruzados de brazos viendo cómo una tentativa de democratización se invalida y mueres ${ }^{31}$. En palabras pronunciadas en un mitin por el canalejista Martínez de Aragón, las izquierdas propugnaron la compatibilidad de ser antirreligioso y católico y urecabar de los poderes la libertad de conciencia y la supremacia del Poder civil» mediante la tolerancia, la libertad de cultos y la separación de la Iglesia del Estado ${ }^{32}$.

Como ya hemos adelantado, la victoria carlista en las elecciones generales de 1910 fue total en Álava ${ }^{33}$. En los distritos donde hubo lucha electoral vencieron los cuneros carlistas: el burgalés Celestino Alcocer en Vitoria y el cántabro Antonio Mazarrasa en Laguardia ${ }^{34}$. Evidentemente, el distrito de Amurrio y las senadurfas quedaron reservadas para la familia Urquijo y sus amigos políticos, o sea, el diputado a Cortes Juan Manuel Urquijo Ussía - en virtud del artículo $29^{35}$ - y los senadores Juan Cano, Estanislao Urquijo Ussía y Carlos Ajuria ${ }^{36}$.

En 1911 cumplieron mandato en el distrito de Laguardia tres diputados carlistas y un liberal-urquijista. El marcado carácter tradicionalista de este distrito y la derechización progresiva de Álava durante el trienio canalejista -materializada en las victorias de los carlistas en las últimas elecciones generales y municipales- parecían vaticinar una clara victoria de los elementos carlistas en las elecciones provinciales de 1911. Pero no fue así.

El Heraldo defendió la postura antagónica, o sea la unión de las derechas, sin distinción de integristas, legitimistas, conservadores e independientes. El telón de fondo de la camparfa no fue la cuestión religiosa, todavía candente a nivel nacional por la política anticlerical canalejista: paradojicamente no apareció ninguna noticia sobre la ley de Asociaciones en relación con las elecciones. En cambio, fue la religión, aunque a nivel provincial, la que centró el interés de

\footnotetext{
3 LL, 18.VI.1910, «De política».

32 Cfr. HA, 11.VII.1910, «Notas vitorianas»; LL, 11.VII.1910, "Vitoria por la Libertad». Los actos de ayers. Un acto progubermamental celebrado en el circo reunió a tres mil personas, según La Libertad -fuente interesada y parcial-. Este periódico se decantó por «la libertad de conciencia (...) la nueva orientación del catolicismo modemistas (LL, 15.X.1910, «La libertad de cultos»).

${ }^{33}$ Cfr. Archivo del Territorio Histórico de Alava (ATHA), D. 2792-1.

${ }^{34}$ Cfr. LL, 12.IV.1910; 21.IIL.1910, «Politica alavesa»; HA, 14.IV.1910; LL, 22.IV.1910, «Politica alavesa»; 2.V.1910, «De elecciones»; 4.V.1910, «De elecciones»; Archivo Dato, carta de L. Irazazábal a E. Dato, 7.III.1910; Archivo Carvajal-Urquijo, Copiador, n. ${ }^{\circ} 278$ y n. 289.

${ }_{35}$ Cfr LL , 9.V.1910, «La jornada de ayen»; HA, 9.V.1910, «Las elecciones de ayer».

36 Cfr. LL, 11.V.1910, «De política»; 14.V.1910, «De senadores; 23.V.1910, «Elecciones senatoriales»; 23.V.1910, «Del día».
} 
la prensa, El Heraldo manifestó «no excluir de la defensa a cuantos querían luchar por Dios y por la Patria ${ }^{37}$ y (rescatar la libertad de la Iglesia ${ }^{38}$, ya que se consideró el defensor por antonomasia de la religión y de la candidatura católica.

La sorpresa de la victoria liberal no fue un misterio, sino que fue fruto de la compra de vatos por los agentes liberales a mejor precio y en mayor número que los carlistas, que también cayeron en las prácticas corruptas del sistema al que tanto criticaban. En algunas ocasiones los antitradicionalistas llegaron a pagar cinco pesetas por voto. De poco sirvió que algunos sacerdotes predicasen a favor de la candidatura carlista, como acaeció en Moreda y Pefíacerrada, donde consiguieron doblar el número de votos con respecto a la Conjunción Liberal. La participación activa de algunos clérigos en política intentó ser frenada por el Obispo de Vitoria, que prohibió al clero diocesano asistir a cualquier acto en centros políticos y también desterró a algún párroco a otro lugar por intervenir en política ${ }^{39}$.

\section{LA DESAPARICIÓN DE LA 《LEY DEL CANDADO»}

El caballo de batalla del nuevo Presidente Romanones, que sustituyó al asesinado Canalejas (12.XI.1912), fue la reforma de la enseñanza ${ }^{40}$, sin variar la política prececente en torno a la cuestión religiosa ${ }^{41}$. Como ya dijimos, Roma-

37 HA, 9.II.1911, «OTRA VEZ. No vinimos a dividir. Queremos la unión».El programa del Heraldo para el afio 1910 se condensó en dos palabras: Dios y Patria (Cfr. HA, 3.I.1910, «Para hoy un paso más»).

${ }^{38} \mathrm{HA}, 10 . \mathrm{I} .1911$, «Los diputados católicos se reunen en banquete».

${ }^{39}$ En efecto, surtió efecto la coacción del cura de Moreda, que dijo que no votar al carlismo era votar al diablo (Cfr. LL, 7.IV.1911). En Peffacerrada el párroco era el responsable del Casino Católico Antiliberal, donde se organizaron las elecciones y se impedía la entrada a cualquier liberal o aquel que desobedeciese las órdenes de los superiores carlistas (Cfr. LL, 7.IV.1911, "¿Se cumple la circular?»). Pocos días después de las elecciones el obispo sustituyó al párroco de Moreda que exhortó a votar a los candidatos jaimistas (Cfr. HA, 27.III.19I1, «Rioja Alavesa. Moreda»). Sin embargo, al mitin del partido jaimista celebrado en junio de 1911 asistieron numerosos sacerdotes, «sin ocultarse de nadie para nadas (LL, 19.VI.1911, «El Obispo y los curas»).

4h La ley de 30 de diciembre de 1912 estableció que las obligaciones de personal y material de primera enseñanza fuesen en lo sucesivo satisfechas por el Estado (Cfr. ATHA, D. 259-15).

${ }^{41}$ El Senado incluyó una prescripción al proyecto de la uley del Candadon aprobado en el Congreso (27.XII.1910) que anunciaba la desaparición de tal ley si en el plazo de dos años no se publicaba un nueva ley de Asociaciones. El Heraldo manifestó su alegría ante la desaparición de una ley «que contra los principios de la libertad que tanto se blasona, impidió el establecimiento de nuevas asociaciones religiosas sin previas y públicas autorizaciones que dificilmente habian de darse» (HA, 8.I.1913, «Albricias! El Candado deshecho»).

Actas del I Congreso de Historia de la Iglesia y el Mundo Hispánico Hispania Sacra, 52 (2000) 
nones fue el autor de la nacionalización definitiva de la enseñanza primaria $(R$. O., 26.X.1901) al asumir el Estado el costo de la instrucción y limitar los intereses de las órdenes religiosas en la enseñanza. La finalidad de la norma centralizadora de Romanones era que el Estado se responsabilizase de la organización y de las competencias en materia educativa. Esta ardua tarea intentó proseguir el Conde de Romanones, aunque esta vez desde la privilegiada posición de la Presidencia del Gobierno. Una medida en la línea liberal y tolerante en favor de una enseñanza neutra fue la publicación de un decreto que anulaba el carácter obligatorio de la enseñanza del catecismo en las escuelas ${ }^{42}$.

En Alava inmediatamente las organizaciones católicas movilizaron a gran parte de la opinión pública «contra los planes sectarios del conde de Romanones en las escuelass ${ }^{43}$. El motor de la protesta fueron las asociaciones y congregaciones religiosas canónicamente constituidas en Vitoria, que contaron con el aliento de las derechas (carlistas, integristas y conservadores), que decidieron apoyar la manifestación en Mạdrid contra las medidas anticlericales ${ }^{44}$. El acto fue retrasado por la efervescencia social que estaba alcanzando el conflicto, y finalmente «el obispo de Madrid, recogiendo instrucciones de Roma, la prohibió de modo terminante» ${ }^{45}$. El obispo de Vitoria autorizó la celebración de Misas en la catedral, en las cuatro parroquias de la capital y en toda la provincia, y exhortó a los niños que se acercasen a comulgar como muestra de protesta y desagravio por el proyecto de enseñanza laica ${ }^{46}$. La fuerte oposición en casi toda España, especialmente en la ultraconservadora Álava, y la falta de respaldo de las izquierdas motivaron que el conde de Romanones retirara el decreto. De otra parte, el gobiemo de Romanones prometió en 1913 que si continuaba la «ley del candado» dos años más no se aprobaría la ley definitiva de Asociaciones. Poco después de esta declaración se restablecieron las relaciones con Roma y nuevas fundaciones solicitaron permiso para establecerse en España. De este

\footnotetext{
42 Sobre las protestas en toda España y las circulares a los Gobernadores Civiles en tomo al problema de la enseñanza del catecismo (cfr. Archivo Romanones, 36-7, 36-10 y 36-19). En las memorias, Romanones aclaró que el mismo sólo dispuso que «no tuviera carácter obligatorio para los hijos de aquellos que, por no pertenecer a la religión católica, creyeran que sus hijos debían estar exentos de recibirlà. El Conde se quejó de la falta de aprecio hacia esta medida por las izquierdas y de la violenta campaña que desencadenaron las derechas contra su persona. Muy afectado añadió que uapenas se dio el caso de ningún padre de familia pidiera que su hijo quedara exento de la enseñanza religiosa (...). Después de esto, y sobre todo falto de apoyo en las izquierdas, sólo me quedaba un camino, el que emprendí: recoger velass) (CONDE DE ROMANONES, Obras completas, vol.III,. Plus Ultra, Madrid, 1949, p. 303-304).

43 HA, 13.III.1913, «La protesta contra el Gobierno».

44 Cfr. LL, 17.V.1913, «Carlistas e integristas a la greña».

45 Conde de Romanones, Obras completas, vol.III, Plus Ultra, Madrid, 1949, p. 304.

46 Cfr. H.A, 2.V.1913, "Vitoria y Álava contra la ensefíanza laica».
} 
modo se cerró un ciclo de la cuestión religiosa en los tres primeros lustros del siglo XX.

\section{CONCLUSIón}

La lucha del Partido Liberal de Canalejas por conseguir más libertades (de cultos, de educación, etc.) y por controlar a las órdenes religiosas fue respondida por los conservadores, carlistas, integristas y nacionalistas con la unión momentanea de todos los tradicionalistas culturalmente católicos en favor de la unión de la Iglesia y del Estado y del mantenimiento del orden tradicional. El resultado fue la victoria de estos últimos dada la preeminencia de la cosmovisión tradicionalista en la Península Ibérica.

Muy distinto fue el resultado en otros países europeos -la kulturkampf de los años setenta en Alemania con la persecución y expulsión de sacerdotes y religiosos y la promulgación de una especie de constitución civil del clero y las leyes educativas de Jules Ferry-, en los que el movimiento modernizador de la secularización fue progresivamente avanzando con menor oposición por parte de los sectores tradicionalistas. 